\title{
Anti-Aversive Effects of Cannabidiol on Innate Fear-Induced Behaviors Evoked by an Ethological Model of Panic Attacks Based on a Prey vs the Wild Snake Epicrates cenchria crassus Confrontation Paradigm
}

\author{
Andrés Uribe-Mariño',2, Audrey Francisco', Maria Angélica Castiblanco-Urbina',2, André Twardowschy', \\ Carlos José Salgado-Rohner', José Alexandre S Crippa ${ }^{3,4}$, Jaime Eduardo Cecílio Hallak ${ }^{3,4}$, \\ Antônio Waldo Zuardi ${ }^{3}$ and Norberto Cysne Coimbra*, 1,2 \\ 'Laboratório de Neuroanatomia and Neuropsicobiologia, Departamento de Farmacologia, Faculdade de Medicina de Ribeirão Preto da \\ Universidade de São Paulo (USP), Ribeirão Preto (SP), Brasil; ${ }^{2}$ Institute for Neuroscience and Behaviour (INeC), Ribeirão Preto (SP), Brazil; \\ ${ }^{3}$ Departamento de Neurociências e Ciências do Comportamento, Setor de Psiquiatria, Faculdade de Medicina de Ribeirão Preto da Universidade \\ de São Paulo (USP), Ribeirão Preto (SP), Brasil; ${ }^{4}$ National Institute for Science and Translational Technology in Medicine (INCT-TM, CNPq), \\ Federal University of Rio Grande do Sul, Brazil
}

\begin{abstract}
Several pharmacological targets have been proposed as modulators of panic-like reactions. However, interest should be given to other potential therapeutic neurochemical agents. Recent attention has been given to the potential anxiolytic properties of cannabidiol, because of its complex actions on the endocannabinoid system together with its effects on other neurotransmitter systems. The aim of this study was to investigate the effects of cannabidiol on innate fear-related behaviors evoked by a prey vs predator paradigm. Male Swiss mice were submitted to habituation in an arena containing a burrow and subsequently pre-treated with intraperitoneal administrations of vehicle or cannabidiol. A constrictor snake was placed inside the arena, and defensive and non-defensive behaviors were recorded. Cannabidiol caused a clear anti-aversive effect, decreasing explosive escape and defensive immobility behaviors outside and inside the burrow. These results show that cannabidiol modulates defensive behaviors evoked by the presence of threatening stimuli, even in a potentially safe environment following a fear response, suggesting a panicolytic effect.
\end{abstract}

Neuropsychopharmacology (2012) 37, 4I2-42I; doi:10.1038/npp.20 I I.I88; published online I4 September 20 I I

Keywords: endocannabinoid-mediated system; cannabidiol; panic-related responses; prey vs predator paradigm; innate fear

\section{INTRODUCTION}

Since the cloning of cannabinoid receptors in the early 1990s, our knowledge of the different sites of action and physiological effects on the brain of the endocannabinoidmediated system has evolved considerably. Consequently, the involvement of the endocannabinoid system in several physiological and behavioral responses has been demonstrated (Crippa et al, 2004; Fride, 2005; Lisboa et al, 2008; Roser et al, 2008). It has also been well established that the

*Correspondence: Professor Dr NC Coimbra, Laboratório de Neuroanatomia and Neuropsicobiologia, Departamento de Farmacologia, Faculdade de Medicina de Ribeirão Preto da Universidade de São Paulo (USP), Avenida dos Bandeirantes, 3900, Ribeirão Preto (SP), |4049-900, Brasil. Tel: +55 |6 3602 3| |6, Fax: + 551636023349 , E-mail: nccoimbr@fmrp.usp.br

Received 4 April 2011; revised 9 August 201 I; accepted 10 August 2011 effects of this neural system are mediated by the actions of endogenous cannabinoids on two different receptors: CB1 and CB2. Whereas CB1 receptors are mostly present in brain, especially neurons, CB2 receptors are mainly expressed in immune cells and tissues (Graham et al, 2009), although the presence of CB2 endocannabinoid receptor in some encephalic structures has been reported (Onaivi et al, 2006).

Research on the interaction between different compounds extracted from the plant Cannabis sativa (Cannabis) and the endocannabinoid system has revealed a series of ligands that selectively bind to cannabinoid receptors. The activation of this system causes a wide spectrum of responses, some of which could be potentially therapeutic. Recently, much attention has been given to cannabidiol (CBD), a major constituent of Cannabis that is unable to mimic all of the effects of the plant but has a wide range of pharmacological effects (Zuardi 2008; Izzo et al, 2009; Crippa et al, 2010). In the elevated plus-maze, this drug 
produces an anxiolytic-like effect in an inverted U-shaped dose-response curve, with higher doses no longer being effective (Guimarães et al, 1990).

CBD could enhance endocannabinoid neurotransmission through an indirect mechanism. CBD has a low affinity for CB1 and CB2 receptors and has the ability to block anandamide's uptake and inhibit its enzymatic hydrolysis (Bisogno et al, 2001; Izzo et al, 2009). In vitro assays have also shown some antagonistic actions of CBD on CB1 and CB2 receptors, which demonstrates complex actions of CBD on the endocannabinoid system (Thomas et al, 2007). Aside from affecting endocannabinoid neurotransmission, CBD interacts with $5-\mathrm{HT}_{1 \mathrm{~A}}$ receptors; there is evidence that $\mathrm{CBD}$ could act, at the micromolar concentration range, as an agonist of $5 \mathrm{HT}_{1 \mathrm{~A}}$ receptors in vitro (Russo et al, 2005) and in vivo (Mishima et al, 2005; Campos and Guimarães, 2008).

Recent attention has been given to the role of the endocannabinoid system in the elaboration and modulation of aversive states in the central nervous system (Moreira et al, 2009a, b; Marco and Viveros, 2009; Thiemann et al, 2009; Fusar-Poli et al, 2009; Mikics et al, 2009; Mackowiak et al, 2009). Results obtained from the elevated plus-maze behavioral test suggest that microinjections of $\mathrm{CB} 1$ receptor agonists into the central nucleus of the amygdaloid complex produce an anxiolytic response that is potentiated by intraperitoneal (i.p.) injections of morphine, a non-selective agonist of opioid receptors (Zarrindast et al, 2008). In addition, the $\mathrm{CB} 1$ receptor has a role in the regulation of aversive states: microinjections of a CB1 receptor agonist followed by an excitatory amino acid into the dorsolateral column of the periaqueductal grey matter (dlPAG) reduce the explosive escape reaction induced by the chemical stimulation of this mesencephalic structure (Finn et al, 2003). In addition, microinjections of CB1 agonists into the dlPAG produce an attenuation of defensive immobility (freezing) and cardiovascular responses in rats submitted to a contextual fearconditioning paradigm (Resstel et al, 2008). These results suggest that the facilitation of endocannabinoid-mediated neurotransmission in the dorsal mesencephalon diminishes the expression of contextual fear-induced responses.

More ethological experimental models of panic attacks have been proposed to better investigate the induction of fear and anxiety-like behaviors, and there is evidence that these responses can be elicited in laboratory animals without prior relevant aversive experience (GuimarãesCosta et al, 2007; Lobão-Soares et al, 2008). Generally, the occurrence of defensive behaviors is closely related to the appearance of threatening scenarios. In this regard, behavioral approaches in rodents involving confrontation with a predator should elicit defensive reactions because of the aversive nature of the encounter and the imminent risk to the rodent (Blanchard et al, 2003). The distinct response pattern of defensive behaviors to drugs that are effective against generalized anxiety disorder or panic syndrome in human subjects indicates that ethological models based on confrontation between prey and predator are appropriate tools for preclinical drug testing for these medical conditions (Griebel et al, 1996; Blanchard et al, 1998; GuimarãesCosta et al, 2007).

The present model is based on the interaction between mice and a wild rainbow Boa and is a novel approach to study the activation of the entire limbic system. Having prey with free movement in a quadrangular arena with a burrow allows for the study of both anxiety- and panic attackrelated behaviors. For example, this is a good model for demonstrating the ethological differences between explosive escape reactions, which are commonly related to the activation of the periaqueductal grey matter and other dorsal mesencephalic structures (Graeff, 1994; Coimbra and Brandão, 1993; Eichenberger et al, 2002; Coimbra et al, 2006; Mobbs et al, 2007), and oriented escape responses (Blanchard et al, 2003; Guimarães-Costa et al, 2007), which are believed to be related to the activation of hypothalamic neurons (Freitas et al, 2009).

The aim of this study was to investigate the effects of the i.p. administration of CBD on the expression of defensive behaviors evoked by an ethological model of panic attacks based on predator threatening stimuli in the presence of wild constrictor Boidae snakes.

\section{SUBJECTS AND METHODS}

\section{Animals}

Male Swiss mice $(25-35 \mathrm{~g})$ from the animal facility of the Ribeirão Preto School of Medicine, University of São Paulo (FMRP-USP), were kept in a 12-h light-dark cycle (lights on from 0700 to 1900 hours) in an air-conditioned room $\left(23 \pm 2{ }^{\circ} \mathrm{C}\right)$ with free access to food and water. The predators used were wild constrictor snakes (Epicrates cenchria crassus; Reptilia; Boidae), weighing $1000-2500 \mathrm{~kg}(n=8)$. The snakes were collected from the Brazilian Southeast, in the countryside of Ribeirão Preto and surrounding districts, and were maintained in captivity in the snake pits of the animal house of the FMRP-USP. They were kept in a walled sun-lit field with proper shelter, grass and water sources in the Laboratory of Neuroanatomy and Neuropsychobiology of the Ribeirão Preto School of Medicine, University of São Paulo (FMRP-USP), licensed by the Brazilian government (IBAMA Committee; process 1/35/1998/000846-1). The snake place of the LNN-FMRP-USP was illuminated by natural sunlight (and by fluorescent ultraviolet irradiation (reptisun; $20 \mathrm{~W}$; 5UVB) on rainy days), and has artificial waterfalls and lagoons, natural rocks, and both tropical and artificial plants. The enclosure was kept under a light-dark cycle of $12-12 \mathrm{~h}$ (lights on from 0700 to 1900 hours) and at a constant room temperature of $25 \pm 1{ }^{\circ} \mathrm{C}(40-70 \%$ humidity). The snakes were fed at two specific times: $24 \mathrm{~h}$ and immediately before the starting of each experiment with rodents of the same species used in this work (Mus musculus). In those occasions, the constrictor snakes evoked hunting behavior and predatory attack, followed by searching responses, capture of the prey, and feeding behavior. The mice were adapted to the experimental rooms for at least 1 week before the experiments, and each mouse was handled for $5 \mathrm{~min}$ on 3 consecutive days before the tests. All tests were performed between 1800 and 2100 hours. The experiments were performed in accordance with the recommendations of the Commission of Ethics in Animal Experimentation of the FMRP-USP (proc. 112/2009), which abides by the ethical principles in animal research adopted by the Brazilian College of Animal Experimentation (COBEA), and was approved by the Commission of Ethics in Animal Research (CETEA) on 31 August 2009. 


\section{Experimental Apparatus}

A semi-transparent acrylic enclosure was used for the prey $v s$ predator confrontations. It consisted of a quadrangular arena $(154 \times 72 \times 64 \mathrm{~cm})$ with the inner surface of its walls covered with a light-reflector film, providing $80 \%$ light reflection, to minimize the visual contact of the predator with the surrounding experimental area and to focus its attention toward the prey. The floor of the quadrangular arena, which was made of a transparent acrylic platform, was placed on a rectangular stainless steel plaque below the arena and was divided into 20 equal rectangles using a green fluorescent line ( $4.2 \mathrm{~mm}$ width; Pritt mark-it). To minimize vibratory stimuli, the entire apparatus was placed on a granite rock surface $(170 \times 85 \times 02 \mathrm{~cm})$ elevated $83 \mathrm{~cm}$ above the floor of the laboratory. In one corner of the arena, a shelter box $(36 \times 26 \times 12.5 \mathrm{~cm})$ with black acrylic walls and a complex labyrinth was placed inside. The burrow had two entries located on opposite sides, thus allowing the rodents to come in and out from two different spots in the arena. On the day of the experiment, the ceiling of the burrow was replaced by an identical model, except it was made of translucent acrylic, to facilitate the recording of the behavior of the mice inside the burrow.

\section{Procedure}

Three days before the experiment, the mice were placed in the arena and maintained there with free access to food and water until the day of the experiment. The burrow was located in a corner, opposite from where the food and water were located. On the day of the experiment, the 'no threat' group was removed from the arena, and the mice were placed inside the arena one at a time to record their behaviors for $5 \mathrm{~min}$ without the snake. The remaining animals that were to be exposed to the predator were divided in four groups ( $n=11-12$ per group), which were pre-treated with i.p. CBD ( $\sim 99.9 \%$ pure, STI-Pharmaceuticals, $\mathrm{UK}$ ) at $0.3,3$, or $30 \mathrm{mg} / \mathrm{kg}$ or its vehicle (saline solution at $0.9 \%$ and DMSO (1:1) $0.2 \mathrm{ml} / \mathrm{kg})$. After $30 \mathrm{~min}$, the snake was carefully placed in the center of the arena, and each mouse was subsequently placed on the opposite side from the burrow, with the snake between the mouse and the burrow. After $5 \mathrm{~min}$ of confrontation, the mouse was removed from the arena with a net, and the snake was placed in the center again. Then, another mouse was placed in the enclosure to confront the snake for the same period of time. No rodent was used in more than one confrontation, and all were killed $24 \mathrm{~h}$ after the experiments. The mice were exposed to the snake randomly between 1800 and 2100 hours.

\section{Anti-Predatory Behavioral Recordings}

The durations and behavioral index (BI) of defensive and non-defensive behaviors of the rodents were recorded. The defensive attention of the rodents was defined as an interruption of on-going behavior for $6 \mathrm{~s}$ to occasionally scan the environment by smelling the surrounding air. Defensive immobility was registered when the mice presented perfect immobility followed by autonomic reactions, such as defecation, exophthalmia, and/or micturition.
Risk assessment was defined as when the rodent stretched its anterior half to monitor behavioral strategies in potentially dangerous situations. Interaction was considered direct contact between prey and predator. Active avoidance behavior was registered when the approaching behavior of the mouse to the snake was suddenly interrupted, and an abrupt change in direction was observed, with the rodent moving in the opposite direction to that of the predator. Oriented escape was defined as running toward the burrow, whereas explosive escape was defined as running toward a direction in the arena other than the burrow. Although regarding exploratory behavior and non-defensive behaviors, crossings, rearing, and grooming were recorded. Crossings were defined as the rodent stepping with its four legs within a delimited rectangle in the arena, after crossing the border of each section. Rearing behavior was recorded when the mice showed an upright posture, stepping with its posterior legs and maintaining its anterior legs in the air or on a wall of the arena or burrow. Finally, grooming referred to self-cleaning behavior.

Considering the complex behavioral repertoire displayed by rodents in confrontations with wild snakes in prey vs predator paradigms (Guimarães-Costa et al, 2007; Lobão-Soares et al, 2008), passive and active avoidance, defensive attention, and risk assessment behaviors were considered anxiety-related responses, and defensive immobility (Borelli et al, 2004), explosive escape reactions (Blanchard et al, 2001; Ribeiro et al, 2005; Castellan-Baldan et al, 2006), and oriented escape behavior (Blanchard et al, 2001; Freitas et al, 2009) were considered panic-like responses.

After the experiment, each snake was transferred to the snake place of the Ribeirão Preto School of Medicine of the University of São Paulo (FMRP-USP), submitted to 40-day quarantine period and, after that, the reptiles were put together with other constrictor snakes of the FMRP-USP main serpentarium. In no case did a snake eat an experimental mouse.

\section{Statistical Analysis}

The frequencies of behaviors were proportionally recorded in relation to the time spent by each animal outside or inside the burrow. These data, presented as a 'behavioral index' (BI), were calculated by the following formula: $\mathrm{BI}=(100 \times$ number of behavioral responses $) /($ time in seconds spent outside or inside the burrow). In addition, the duration of each behavior was expressed as the percentage between the total time of the experiment and the time spent in a given behavioral response evoked outside or inside the burrow. The data were analyzed by one-way ANOVA, and the Newman-Keuls test was employed for multiple comparisons. Data are presented as mean and SEM. Differences were considered significant at $P<0.05$.

\section{RESULTS}

After 3 days of habituation, mice in the non-threatened group did not exhibit fear-like behaviors but did show mild defensive attention and risk assessment behaviors during the mock predatory test, which was expected because the 
mice were individually exposed to the polygonal arena without nest material, food, or water, which was a change from the previous appearance of the same environment during habituation.

Once habituated to the arena for 3 days, after the pretreatment with i.p. administration of either vehicle or CBD at different doses and after being exposed to the arena with the constrictor snake, all mice exhibited a series of defensive behaviors characterized by defensive attention, risk assessment, active avoidance, defensive immobility, explosive escape responses, and oriented escape behavior directed to the burrow. During the interaction with the predator, nondefensive behaviors, such as rearing and grooming, were also observed in all animals. Interestingly, once safely inside the burrow, mice showed almost the same pattern of defensive and non-defensive behaviors, although with lower intensities and durations.

On the other hand, the predators showed moderate exploratory behavior inside the arena, with interspersed resting periods and occasional entries into the burrow. Furthermore, after the interaction between prey and predator, the constrictor snakes defensive reactions characterized by head retrieval or movements of the anterior third of the body to the side opposite to that occupied by the prey. All rodents displayed defensive behaviors to the spontaneous exploratory activity of the constrictor snake and to the predator's defensive reactions.

With regard to the behavioral responses elicited outside the burrow, the vehicle-treated group of mice that were exposed to the predator showed increases in the duration $(\mathrm{F}(4,58)=6.82 ; P<0.05)$ and $\mathrm{BI}(\mathrm{F}(4,58)=6.95 ; P<0.05)$ of risk assessment and the duration of defensive attention $(\mathrm{F}(4,59)=4.30 ; P<0.05)$ when compared with the nonthreatened group (Figures 1a-d). There was no effect of CBD at any dose on the duration or BI of defensive attention, risk assessment, or interaction with the predator outside the burrow when compared with the vehicle-treated group (Figures $1 \mathrm{a}-\mathrm{f}$ ). In contrast, CBD at 3 and $30 \mathrm{mg} / \mathrm{kg}$ reduced the duration $(\mathrm{F}(3,43)=3.83 ; P<0.05)$ and $\mathrm{BI}$ $(\mathrm{F}(3,43)=3.45 ; P<0.05)$ of active avoidance when compared with the vehicle-treated group (Figures $1 \mathrm{~g}$ and $\mathrm{h}$ ).

With regard to the expression of innate fear-related behaviors outside the burrow, the one-way ANOVA revealed significant differences for the durations and behavioral indices of defensive immobility, explosive escape, and total escape (Figures $2 \mathrm{a}-\mathrm{h}$ ). Post hoc analysis using the Newman-Keuls multiple comparison test showed significant increases in the behavioral indices and durations of defensive immobility $(\mathrm{F}(4,58)=4.81 ; P<0.05$ and $\mathrm{F}(4,57)=3.03 ; \quad P<0.05$, respectively), explosive escape $(\mathrm{F}(4,59)=7.25 ; P<0.05$ and $\mathrm{F}(4,58)=5.41 ; P<0.05$, respectively) and total escape $(\mathrm{F}(4,59)=12.07 ; P<0.05$ and $\mathrm{F}(4,59)=10.10 ; P<0.05$, respectively) exhibited by the vehicle-treated group compared with the non-threatened group. The animals pre-treated with $\mathrm{CBD}$ showed significant decreases in the BI (all doses: $\mathrm{F}(4,58)=4.81 ; P<0.05$ ) and duration $(3 \mathrm{mg} / \mathrm{kg}: \mathrm{F}(4,57)=3.04 ; P<0.05)$ of defensive immobility, the BI ( 3 and $30 \mathrm{mg} / \mathrm{kg}: \mathrm{F}(4,59)=7.25 ; P<0.05)$ and duration ( 3 and $30 \mathrm{mg} / \mathrm{kg}: \mathrm{F}(4,59)=5.40 ; P<0.05)$ of explosive escape and the BI (all doses: $\mathrm{F}(4,59)=12.07$; $P<0.05)$ and the duration $(3$ and $30 \mathrm{mg} / \mathrm{kg}: \mathrm{F}(4,59)=10.10$; $P<0.05)$ of total escape when compared with the vehicle-
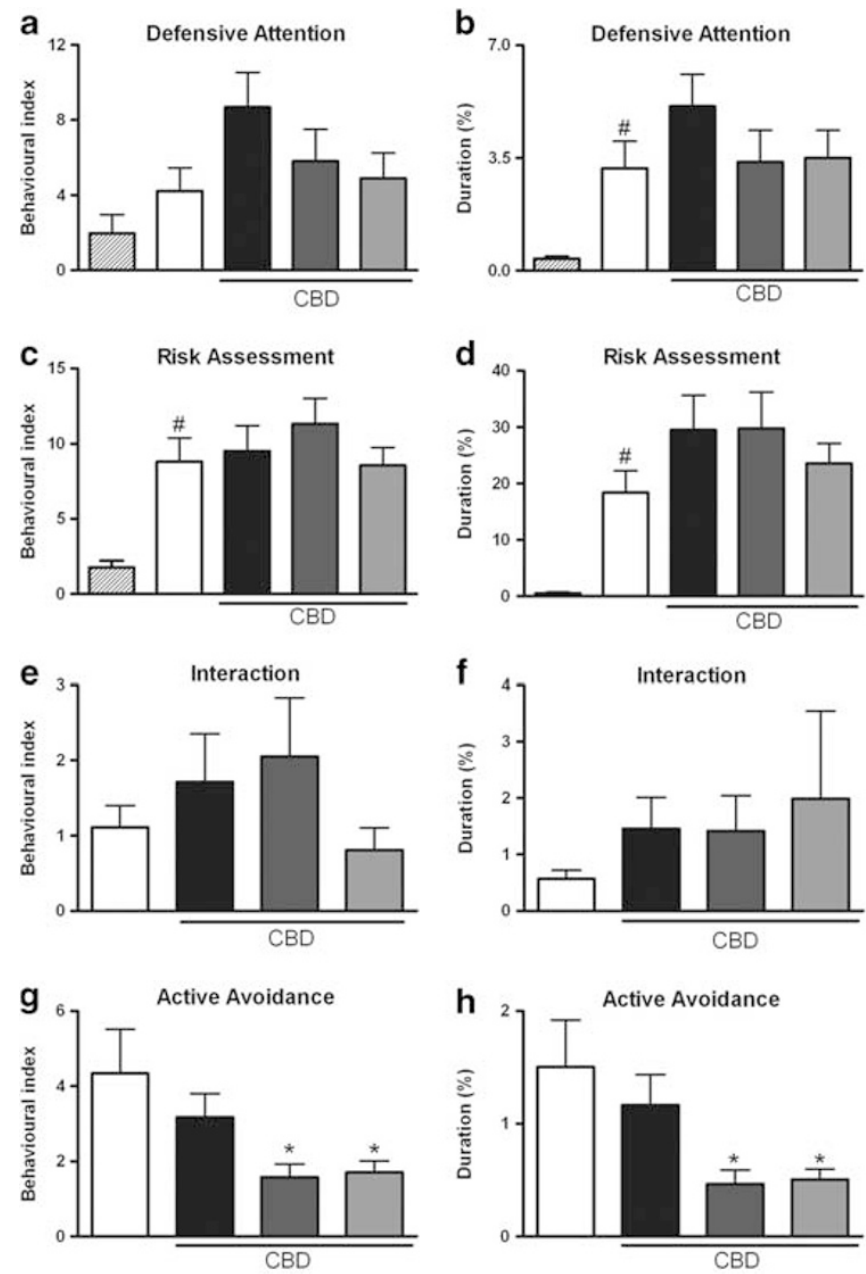

No Threat

Vehicle

$0.3 \mathrm{mg} / \mathrm{kg}$

$3 \mathrm{mg} / \mathrm{kg}$

$30 \mathrm{mg} / \mathrm{kg}$

Figure I Outside-burrow behaviors. Non-threatened mouse behaviors and the effects of intraperitoneal administration of vehicle or cannabidiol (CBD) at $0.3,3$, or $30 \mathrm{mg} / \mathrm{kg}$ on the behavioral index (BI) (a) and duration (b) of defensive attention, the $\mathrm{BI}$ (c) and duration (d) of risk assessment, the $\mathrm{BI}(\mathrm{e})$ and duration ( $\mathrm{f}$ ) of the interaction between prey and snake, and the $\mathrm{BI}(\mathrm{g})$ and duration ( $h$ ) of active avoidance exhibited by mice during the confrontation with the wild constrictor snake after a 3-day habituation period in a polygonal arena. Columns represent the mean and bars the SEM, $n=11-12$ mice per group. ${ }^{\#} P<0.05$ when compared with the group not submitted to any threatening situation (no-threat); $* P<0.05$ when compared with the vehicle-treated group. $\mathrm{BI}=(100 \times$ number of behavioral responses)/(time in seconds spent outside or inside the burrow).

treated group. The one-way ANOVA did not show a statistically significant difference in oriented escape behavior in CBD-treated mice (Figures 2e and $\mathrm{f}$ ).

For the non-defensive behaviors displayed outside the burrow, the one-way ANOVA showed that the presence of the predator altered only the $\mathrm{BI}$ of rearing $(\mathrm{F}(4,59)=12.45$; $P<0.05$ ), as shown in Figure $3 \mathrm{a}$, while the durations of rearing, grooming, crossings and time spent outside the burrow were not significantly changed (Figures $3 b-f$ ). In contrast, pre-treatment of mice with $\mathrm{CBD}$ reduced the $\mathrm{BI}$ (all doses: $\mathrm{F}(4,59)=12.45 ; P<0.05)$ and duration (all doses: $\mathrm{F}(4,59)=7.17 ; P<0.05)$ of rearing, the quantity of crossings (all doses: $\mathrm{F}(4,42)=19.01 ; P<0.05)$ and the time spent outside the burrow ( 3 and $30 \mathrm{mg} / \mathrm{kg}: \quad F(4,56)=6.04$; 

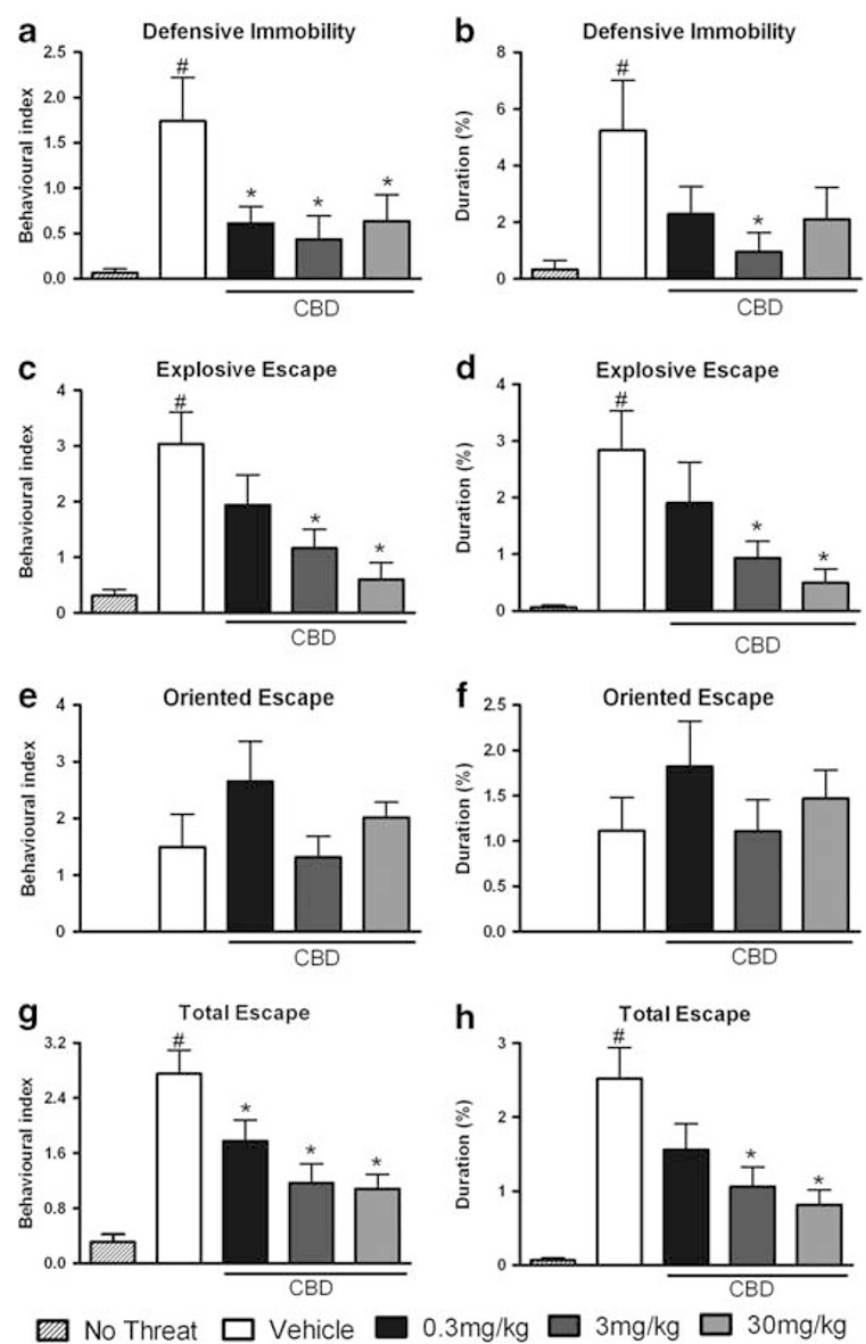

No Threat
$0.3 \mathrm{mg} / \mathrm{kg}$
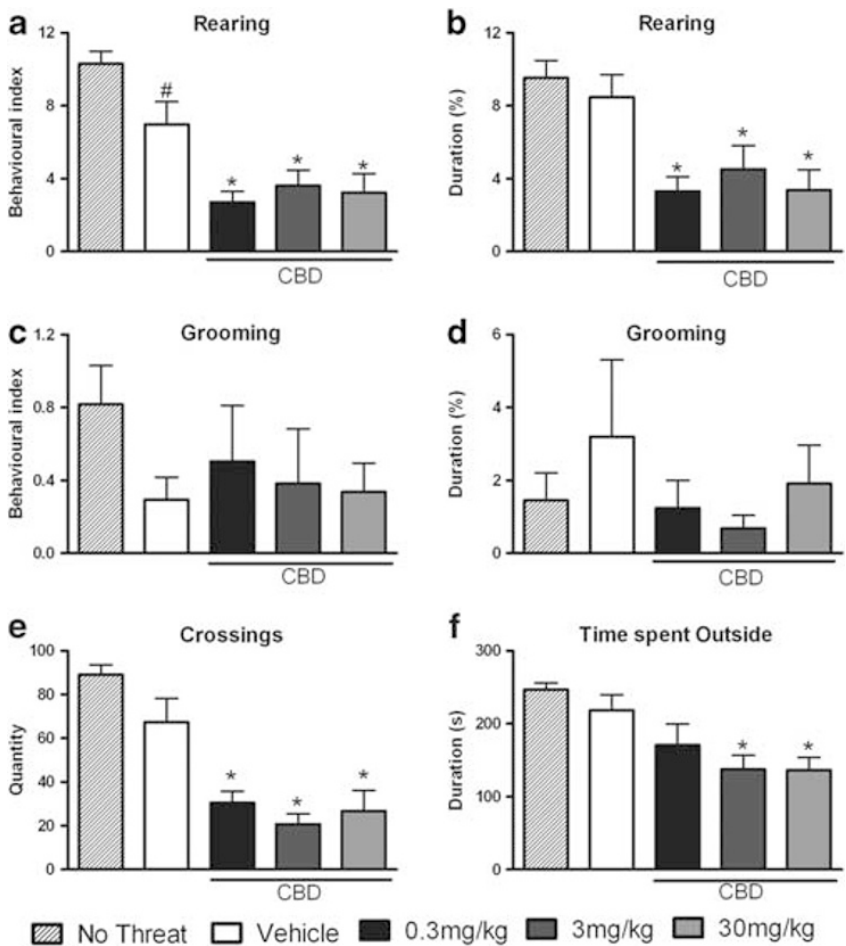

Figure 3 Outside-burrow behaviors. Non-threatened mouse behaviors and the effects of intraperitoneal administration of vehicle or cannabidio (CBD) at $0.3,3$, or $30 \mathrm{mg} / \mathrm{kg}$ on the behavioral index (BI) (a) and duration (b) of rearing, the $\mathrm{BI}$ (c) and duration (d) of grooming, the quantity of crossings (e) and the duration of the time spent outside the burrow ( $f$ ) exhibited by mice during the confrontation with the wild constrictor snake after a 3-day habituation period in a polygonal arena. Columns represent the mean and bars the SEM, $n=1 \mid-12$ mice per group. ${ }^{\#} p<0.05$ when compared with the group not submitted to any threatening situation (nothreat); ${ }^{*} P<0.05$ when compared with the vehicle-treated group. $\mathrm{BI}=(100 \times$ number of behavioral responses $) /($ time in seconds spent outside or inside the burrow).

Figure 2 Outside-burrow behaviors. Non-threatened mouse behaviors and the effects of intraperitoneal administration of vehicle or cannabidiol (CBD) at $0.3,3$, or $30 \mathrm{mg} / \mathrm{kg}$ on the behavioral index (BI) (a) and duration (b) of defensive immobility, the BI (c) and duration (d) of explosive escape responses, the $\mathrm{BI}(\mathrm{e})$ and duration ( $\mathrm{f}$ ) of oriented escape responses and the $\mathrm{BI}(\mathrm{g})$ and duration ( $\mathrm{h}$ ) of the total escape response exhibited by mice during the confrontation with the wild constrictor snake after a 3-day habituation period in a polygonal arena. Columns represent the mean and bars the SEM, $n=11-12$ mice per group. ${ }^{\#} P<0.05$ when compared with the group not submitted to any threatening situation (no-threat); ${ }^{*} P<0.05$ when compared with the vehicle-treated group. $\mathrm{Bl}=(\mathrm{I} 00 \times$ number of behavioral responses)/(time in seconds spent outside or inside the burrow).

$P<0.05)$ when compared with the vehicle-treated group. Moreover, CBD had no effect on grooming behavior. These data are presented in Figures $3 \mathrm{a}-\mathrm{f}$.

Once inside the burrow, all threatened mice exhibited defensive behaviors with a similar phenomenology to that observed outside the burrow, although there was an oscillation in the BI and the duration of each defensive response, and both non-defensive and exploratory behavior were also exhibited, as shown in Figures 4 and 5. In fact, there was a statistically significant difference between the vehicle-treated group and non-threatened group in the BI $(\mathrm{F}(4,59)=5.61 ; P<0.05)$ and the duration $(\mathrm{F}(4,59)=3.36$; $P<0.05)$ of defensive attention directed either at the entry or at the inner spaces, suggesting an alertness state in case of an occasional predator sighting near or inside the burrow (Figures $4 \mathrm{a}$ and b). Moreover, exploratory and restless behaviors were decreased in the vehicle-treated group of threatened mice: they showed reductions in the $\mathrm{BI}$ $(\mathrm{F}(4,59)=7.99 ; \quad P<0.05)$ and duration $(\mathrm{F}(4,59)=8.09$; $P<0.05)$ of rearing and a reduction in the $\mathrm{BI}$ of grooming $(\mathrm{F}(4,59)=2.18 ; P<0.05)$ when compared with the nonthreatened group, as shown in Figures $4 \mathrm{e}-\mathrm{g}$. In addition, the vehicle-treated mice exhibited increased behavioral indices and durations of explosive escape $(\mathrm{F}(4,59)=8.88 ; P<0.05$ and $\mathrm{F}(4,59)=6.07 ; P<0.05$, respectively) and defensive immobility $(\mathrm{F}(4,59)=4.33 ; P<0.05$ and $\mathrm{F}(4,58)=3.76$; $P<0.05$, respectively), showing that the animals continued to display fear-like behaviors inside the burrow, as shown in Figures 5a-d. Furthermore, post hoc analysis using the Newman-Keuls multiple comparison test revealed significant decreases caused by CBD in the behavioral indices and durations of explosive escape behavior (all doses: $\mathrm{F}(4,59)=8.88 ; P<0.05$ and $\mathrm{F}(4,59)=6.07 ; P<0.05$, respectively) and defensive immobility (all doses $\mathrm{F}(4,59)=4.33$; $P<0.05$ and at $3 \mathrm{mg} / \mathrm{kg} \mathrm{F}(4,58)=3.76 ; P<0.05$, respecinside the burrow were not significantly different between tively) (Figures $5 \mathrm{a}-\mathrm{d}$ ). The number of entries and time spent 

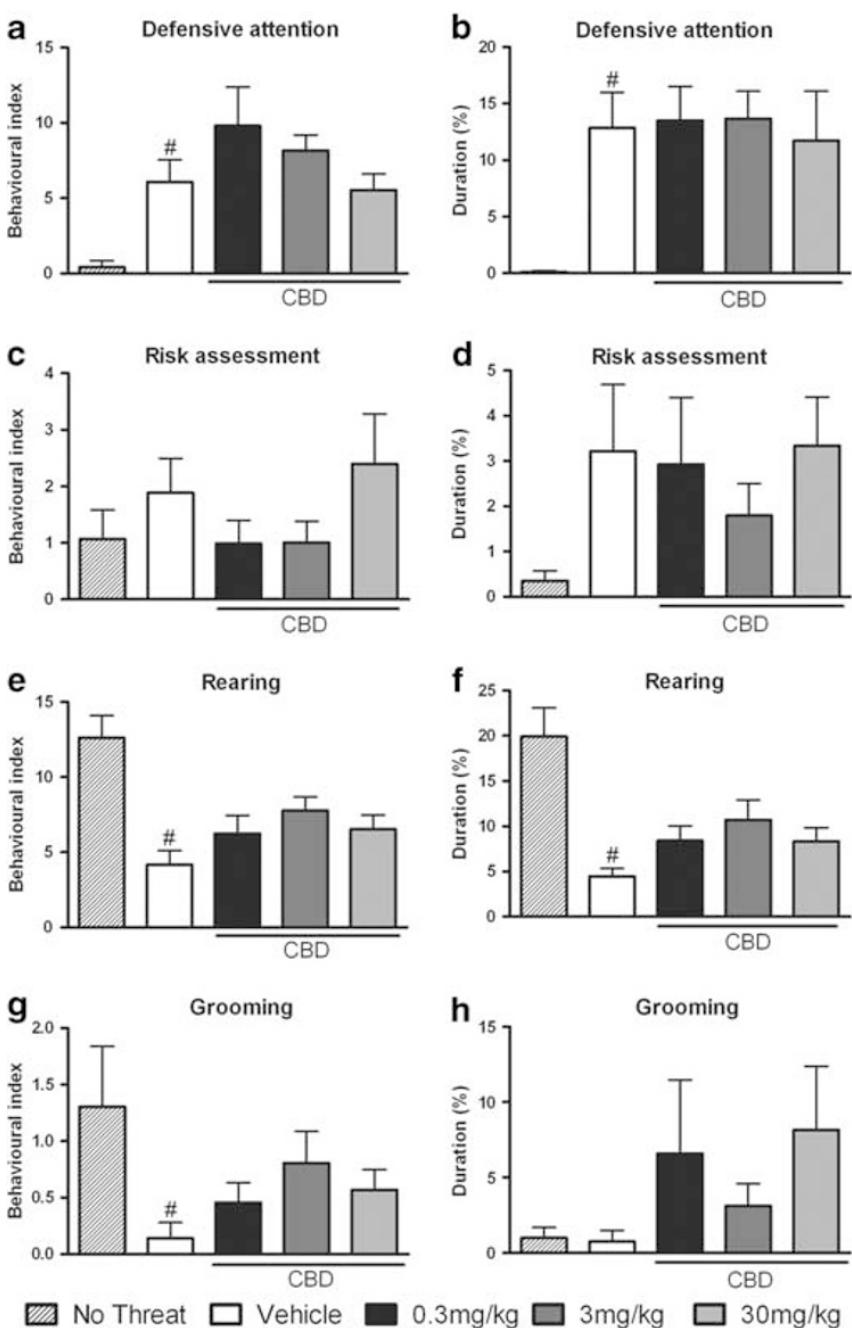

No Threat

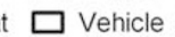

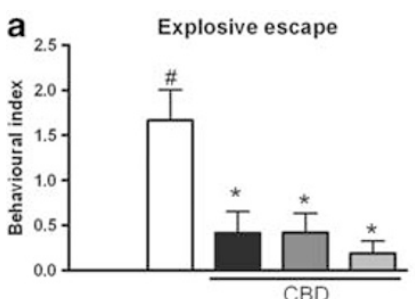
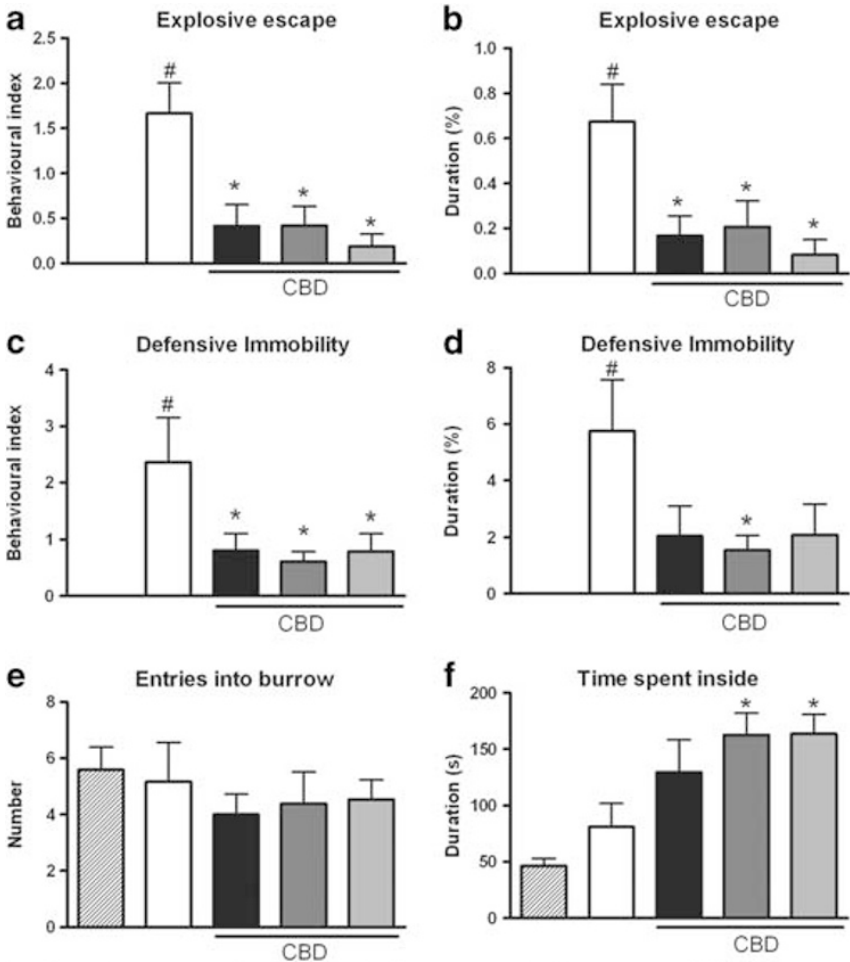

No Threat

Vehicle

$0.3 \mathrm{mg} / \mathrm{kg} \square 3 \mathrm{mg} / \mathrm{kg}$

Figure 5 Inside-burrow behaviors. Non-threatened mouse behaviors and the effects of intraperitoneal administration of vehicle or cannabidiol (CBD) at $0.3,3$, or $30 \mathrm{mg} / \mathrm{kg}$ on the behavioral index (BI) (a) and duration (b) of explosive escape, the BI (c) and duration (d) of defensive immobility, the number of entries (e) into the burrow and the duration ( $f$ ) of time spent inside by mice during the confrontation with the wild constrictor snake after a 3-day habituation period in the arena. Columns represent the mean and bars the SEM, $n=11-12$ per group. ${ }^{\#} P<0.05$ when compared with the group not submitted to any threatening situation (no-threat); * $P<0.05$ when compared with the vehicle-treated group. $\mathrm{BI}=(\mathrm{I} 00 \times$ number of behavioral responses)/(time in seconds spent outside or inside

Figure 4 Inside-burrow behaviors. Non-threatened mouse behaviors and the effects of intraperitoneal administration of vehicle or cannabidiol (CBD) at $0.3,3$, or $30 \mathrm{mg} / \mathrm{kg}$ on the behavioral index (BI) (a) and duration (b) of defensive attention, the $\mathrm{BI}$ (c) and duration (d) of risk assessment, the $\mathrm{BI}(\mathrm{e})$ and duration ( $\mathrm{f}$ ) of rearing and the $\mathrm{BI}(\mathrm{g})$ and duration (h) of grooming exhibited by mice during the confrontation with the wild constrictor snake after a 3-day habituation period in the arena. Columns represent the mean and bars the SEM, $n=1 \mid-12$ mice per group. ${ }^{\#} P<0.05$ when compared with the group not submitted to any threatening situation (no-threat). $\mathrm{BI}=(100 \times$ number of behavioral responses)/(time in seconds spent outside or inside the burrow).

the vehicle-treated group and non-threatened group, but the CBD-pre-treated animals spent more time inside the burrow ( 3 and $30 \mathrm{mg} / \mathrm{kg}: \mathrm{F}(4,55)=6.42 ; P<0.05)$ compared with the vehicle-treated group, as shown in Figures $5 \mathrm{e}$ and $\mathrm{f}$.

In the comparison of the defensive behaviors displayed by threatened animals inside and outside the burrow (Figure 6), one-way ANOVA did not show significant differences in the $\mathrm{BI}$ or the duration of defensive attention (Figures $6 \mathrm{a}$ and $\mathrm{b}$ ) nor in the BI or the duration of defensive immobility (Figures $6 \mathrm{~g}$ and $\mathrm{h}$ ). In contrast, post hoc analysis using the Newman-Keuls multiple comparison test revealed a significant decrease in the behavioral indices and durations of risk assessment (all doses: $\mathrm{F}(7,96)=13.45 ; P<0.05$ and $\mathrm{F}(7,96)=11.37 ; P<0.05$, respectively) and explosive escape (vehicle and $0.3 \mathrm{mg} / \mathrm{kg}$ of $\mathrm{CBD}: \mathrm{F}(7,96)=8.70 ; P<0.05$ and

\section{the burrow).}

$\mathrm{F}(7,97)=5.77 ; P<0.05$, respectively) inside the burrow in relation those responses outside the burrow within each treatment group, as shown in Figures $6 c-f$.

\section{DISCUSSION}

During the habituation period, exploratory behaviors were observed throughout the different spaces of the arena and the burrow, and food was stored inside the burrow. The group of animals that were not exposed to a confrontation with the wild snake, but only to the polygonal arena, did not exhibit any defensive-like behavior. In addition, while the illumination of the arena during the recordings of the behavioral responses could be aversive to the albino mice submitted to the experiment, they expressed neither anxiety-like responses nor panic-like behaviors during the habituation period. However, when exposed to the predator in the same context after 3 days of habituation, all mice exhibited defensive behaviors. Sometimes, threatened animals would run to the burrow during the confrontation with the predator. However, considering the possibility of an 


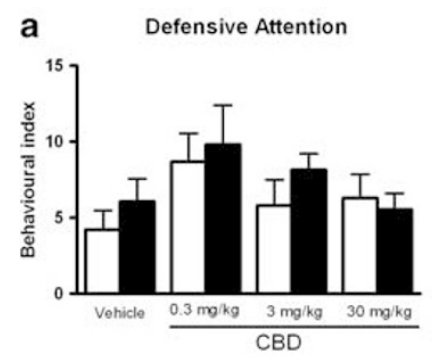

b Defensive Attention
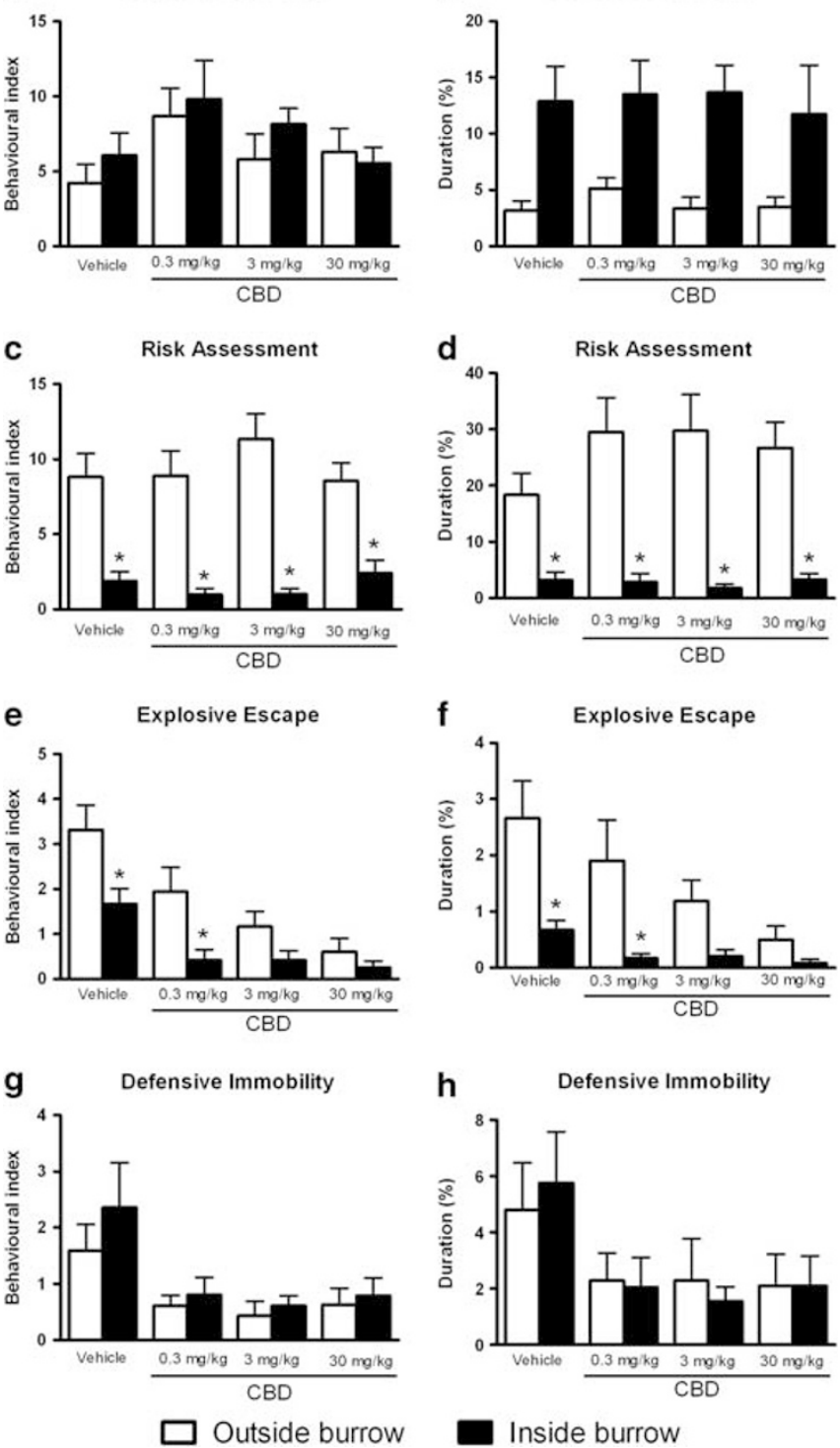

h

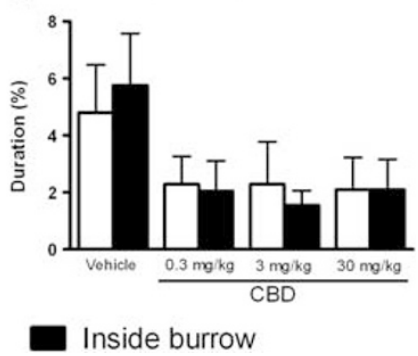

Figure 6 Outside- vs inside-burrow behaviors. Effects of intraperitoneal administration of vehicle or cannabidiol (CBD) at $0.3,3$, or $30 \mathrm{mg} / \mathrm{kg}$ on the behavioral index (BI) (a) and duration (b) of defensive attention, the $\mathrm{BI}(\mathrm{c})$ and duration (d) of risk assessment, the $\mathrm{Bl}(\mathrm{e})$ and duration (f) of explosive escape response, and the $\mathrm{Bl}(\mathrm{g})$ and duration $(\mathrm{h})$ of defensive immobility exhibited by mice during the confrontation with the wild constrictor snake after a 3-day habituation period in the polygonal arena. Columns represent the mean and bars the SEM, $n=11-12$ mice per group. $* P<0.05$ when compared with the respective treatment outside the burrow. $\mathrm{BI}=(\mathrm{I} 00 \times$ number of behavioral responses)/(time in seconds spent outside or inside the burrow).

invasion of the burrow by the predator, immediately after a confrontation, some aversive stimulus-induced reactions could be elicited, even in that potentially safe environment.

In addition, brief interaction periods between rodents and snakes evoked prompt defensive reactions in the predator as well, which, in turn, caused panic-like reactions, such explosive escape, in the mice. The patterns just described clearly resemble those observed in more naturalistic environments, suggesting that the experimental design constitutes a more ethological approach to the study of innate fear-induced reactions and panic attacks.
Mice pre-treated with CBD showed a significant and robust reduction in explosive escape (flight) and defensive immobility (freezing), responses that are considered paniclike behaviors (Griebel et al, 1996; Blanchard et al, 2001; Borelli et al, 2004, 2005). In addition, a response of active avoidance, in which the mouse reacts with vigorous movement to avoid close contact with the snake, was reduced by $\mathrm{CBD}$, suggesting that these mice felt less fear in the presence of a potential predator. In contrast, typical anxiety-related behaviors, such as risk assessment and defensive attention (Blanchard et al, 2001; Lobão-Soares et al, 2008), were unchanged in the animals that received CBD. Anxiety and panic states involve different neural substrates, particular physiological responses and characteristic motor behaviors (Gorman et al, 2000). In addition, anxiety and panic are evoked by different scenarios. Generally, defensive behaviors, such as defensive attention and risk assessment, are responses to situations of potential danger in which an aversive stimulus is at a distance or its source has not yet been identified (Blanchard et al, 2003; Motta et al, 2009). However, responses such as oriented and explosive escape and defensive immobility are exhibited in circumstances in which the aversive stimulus is not only present but within a proximal distance and represents a clear threat to the survival of the organism (GuimarãesCosta et al, 2007; Blanchard et al, 2003). Thus, the present findings suggest that $\mathrm{CBD}$, in the present experimental model of panic attacks, decreases the behavioral responses associated with settings of imminent danger in which the aversive connotation of the stimulus has been fully recognized.

Oriented escape has been associated with aversive scenarios that contain an available route of escape that provides the organism with a secure way out (Blanchard et al, 2003; Blanchard and Blanchard, 1999). In this regard, oriented escape behavior represents patterns of action that allow more efficient and organized responses in aversive situations, such as those involving the presence of a predator. More disorganized reactions, such as explosive escape, are exhibited in circumstances in which extremely aversive events impose the execution of physiological and motor reactions aimed at directing the organism away from the dangerous situation. Interestingly, animals treated with CBD did not show a statistically significant difference in oriented escape behavior in relation to untreated mice. In addition, peripheral treatment with CBD caused a reduction in the time spent outside the burrow and decreased the number of crossings, suggesting that these animals had a preference to stay inside the burrow to avoid a possible confrontation with the predator. However, when CBDtreated animals were inside the burrow, they expressed fewer panic-like behaviors, such as explosive escape and defensive immobility, compared with the vehicle-treated group, suggesting that the treatment with $\mathrm{CBD}$ is able to reduce the panic-induced responses not only in the presence of the snake but even in a potentially safe place and immediately after the exposure to a threatening situation.

The present findings show that when defensive behaviors evoked outside the burrow were compared with those evoked inside the burrow following exposure to a threatening environment, significant decreases were observed in 
panic-induced responses. This result clearly suggests that, as expected, the burrow could not only diminish, but even suppress, the expression of some fear-related behavior. Thus, this space could represent a safe place for the rodents, given its low illumination and narrow passages, bringing more security and thus decreasing fear-related responses. Consequently, the burrow itself could have acted as a shelter and had an anxiolytic and panicolytic effect on the limbic system. The risk assessment behavior displayed inside the burrow was characterized by the mouse extending its anterior half of the body outside of the burrow while maintaining its posterior half inside, supporting the idea that the burrow provides a more secure environment to which the mouse could return rapidly in the case of predator approach.

In humans, the anxiolytic effects of CBD have been associated with a decrease in the activity of limbic structures. A recent study using functional magnetic resonance imaging in healthy volunteers showed that $\mathrm{CBD}$ can modulate the patterns of brain activity during the viewing of fearful facial stimuli, attenuating neural activity in the amygdaloid complex and in the anterior and posterior cingulate cortex (Fusar-Poli et al, 2009). In addition, interactions between $\mathrm{CBD}$ and the serotoninergic receptors in the mesencephalic and prosencephalic structures of the brain aversion system have recently been reported, which could also help explain the effects observed in this study (Campos and Guimarães, 2008; Canteras et al, 1997; Resstel et al, 2009; Russo et al, 2005). Serotonin has an important role in the regulation of defensive behaviors (de Paula Soares and Zangrossi, 2004; Graeff et al, 1986). In healthy volunteers submitted to the simulated public speaking test, CBD attenuated the anxiety induced in a similar manner to ipsapirone, an agonist of the $5 \mathrm{HT}_{1 \mathrm{~A}}$ receptor (Zuardi et al, 1993). This study employed an animal model of panic attacks, which could resemble the physiological and behavioral reactions experienced by patients with panic disorder (Pollack and Marzol, 2000), for whom the most effective pharmacological intervention is based on antidepressant drugs that enhance serotoninergic neurotransmission (Simon et al, 2009; Kellner et al, 2009).

In summary, the data presented in this study suggest that the complex action of CBD on the endocannabinoidmediated system, together with its putative effect on the serotonin-mediated system, could have a pivotal role in the regulation of emotional states and thus constitute a novel pharmacological target for anti-panic therapy. Finally, the present findings demonstrate that the ethological model of panic attacks based on a snake and rodent interaction paradigm constitutes a good tool to address new approaches that focus on the pharmacological actions of new antiaversive or panicolytic drugs.

\section{ACKNOWLEDGEMENTS}

This study was supported by CNPq (proc. 470119/2004-7), FAEPA (proc. 1291/97, 355/2000, 68/2001 and 15/2003), and FAPESP (proc. 03/07202-6, 03/01768-8, 03/01794-9, and 07/ 01174-1). A Uribe-Mariño (proc. FAPESP 2009/01153-0, MSc), A Francisco (proc. FAPESP 2008/08955-1; MSc), MA Castiblanco-Urbina (proc. FAPESP 2009/01157-5; MSc), A
Twardowschy (proc. FAPESP 2008/00531-8; DSc), and CJ Salgado-Rohner (proc. CNPq 135930/2009-0; MSc) were supported by FAPESP and CNPq fellowships. NC Coimbra was granted a research fellowship (level $1 \mathrm{~A}$ ) from $\mathrm{CNPq}$ (proc. 301905/2010-0) and was a CNPq-Post-doctoral fellow (proc. 200629/2005-0) in the Physiology, Anatomy and Genetics Department and in the Clinical Neurology (FMRIB Centre) Department of the University of Oxford, England, UK. JAS Crippa (1C), AW Zuardi (1B) and JEC Hallak (2) are recipients of CNPq Productivity Awards. The authors are grateful to DH Elias-Filho for expert technical assistance. DH Elias Filho received a technician scholarship from FAPESP (TT-2, proc. 02/01497-1) and was the recipient of scholarships sponsored by CNPq (proc. 501858/2005-9, 500896/2008-9, and 505461/2010-2).

\section{DISCLOSURE}

The authors declare no conflict of interest.

\section{REFERENCES}

Bisogno T, Hanus L, de Petrocellis L, Tchilibon S, Ponde DE, Brandi I et al (2001). Molecular targets for cannabidiol and its synthetic analogues: effect on vanilloid VR1 receptors and on the cellular uptake and enzymatic hydrolysis of anandamide. $\mathrm{Br} \mathrm{J}$ Pharmacol 134: 845-852.

Blanchard DC, Blanchard RJ (1999). Cocaine potentiates defensive behaviors related to fear and anxiety. Neurosci Biobehav Rev 23: 981-991.

Blanchard DC, Griebel G, Blanchard RJ (2001). Mouse defensive behaviors: pharmacological and behavioral assays for anxiety and panic. Neurosci Biobehav Rev 25: 205-218.

Blanchard DC, Griebel G, Blanchard RJ (2003). The mouse defense test battery: pharmacological and behavioral assays for anxiety and panic. Eur J Pharmacol 463: 97-116.

Blanchard DC, Griebel G, Rodgers RJ, Blanchard RJ (1998). Benzodiazepine and serotonergic modulation of antipredator and conspecific defense. Neurosci Biobehav Rev 22: 597-612.

Borelli KG, Ferreira-Netto C, Coimbra NC, Brandão ML (2005). Fos-like immunoreactivity in the brain associated with freezing or escape induced by inhibition of either glutamic acid decarboxylase or $\mathrm{GABA}_{\mathrm{A}}$ receptors in the dorsal periaqueductal gray. Brain Res 1051: 100-111.

Borelli KG, Nobre MJ, Brandão ML, Coimbra NC (2004). Effects of acute and chronic fluoxetine and diazepam on freezing behavior induced by electrical stimulation of dorsolateral and lateral columns of the periaqueductal gray matter. Pharmacol Biochem Behav 77: 557-566.

Campos AC, Guimarães FS (2008). Involvement of $5 \mathrm{HT}_{1 \mathrm{~A}}$ receptors in the anxiolytic-like effects of cannabidiol injected into the dorsolateral periaqueductal gray of rats. Psychopharmacology (Berl) 199: 223-230.

Canteras NS, Chiavegatto S, Valle LE, Swanson LW (1997). Severe reduction of rat defensive behavior to a predator by discrete hypothalamic chemical lesions. Brain Res Bull 44: 297-305.

Castellan-Baldan L, da Costa Kawasaki M, Ribeiro SJ, Calvo F, Corrêa VMA, Coimbra NC (2006). Topographic and functional neuroanatomical study of GABAergic disinhibitory striatumnigral inputs and inhibitory nigrocollicular pathways: neural hodology recruiting the substantia nigra, pars reticulata, for the modulation of the neural activity in the inferior colliculus involved with panic-like emotions. J Chem Neuroanat 32: 1-27.

Coimbra NC, Brandão ML (1993). GABAergic nigro-collicular pathways modulate the defensive behaviour elicited by midbrain tectum stimulation. Behav Brain Res 59: 131-139. 
Coimbra NC, de Oliveira R, Freitas RL, Ribeiro SJ, Borelli KG, Pacagnella RC et al (2006). Neuroanatomical approaches of the tectum-reticular pathways and immunohistochemical evidence for serotonin-positive perikarya on neuronal substrates of the superior colliculus and periaqueductal gray matter involved in the elaboration of the defensive behavior and fear-induced analgesia. Exp Neurol 197: 93-112.

Crippa JA, Zuardi AW, Garrido GE, Wichert-Ana L, Guarnieri R, Ferrari L et al (2004). Effects of cannabidiol (CBD) on regional cerebral blood flow. Neuropsychopharmacology 29: 417-426.

Crippa JAS, Zuardi AW, Hallak JEC (2010). Therapeutical use of the cannabinoids in psychiatry. Rev Bras Psiquiatr 32: 56-65.

de Paula Soares V, Zangrossi H (2004). Involvement of 5- $\mathrm{HT}_{1 \mathrm{~A}}$ and $5-\mathrm{HT}_{2}$ receptors of the dorsal periaqueductal gray in the regulation of the defensive behaviors generated by the elevated T-maze. Brain Res Bull 64: 181-188.

Eichenberger GCD, Ribeiro SJ, Osaki MY, Maruoka RY, Resende GCC, Castellan-Baldan L et al (2002). Neuroanatomical and psychopharmacological evidence for interaction between opioid and GABAergic neural pathways in the modulation of fear and defense elicited by electrical and chemical stimulation of the deep layers of the superior colliculus and dorsal periaqueductal gray matter. Neuropharmacology 42: 48-59.

Finn DP, Jhaveri MD, Beckett SR, Roe CH, Kendall DA, Marsden CA et al (2003). Effects of direct periaqueductal grey administration of a cannabinoid receptor agonist on nociceptive and aversive responses in rats. Neuropharmacology 45: 594-604.

Freitas RL, Uribe-Mariño A, Castiblanco-Urbina MA, Elias-Filho $\mathrm{DH}$, Coimbra NC (2009). GABA $\mathrm{A}$ receptor blockade in dorsomedial and ventromedial nuclei of the hypothalamus evokes paniclike elaborated defensive behaviour followed by innate fearinduced antinociception. Brain Res 1305: 118-131.

Fride E (2005). Endocannabinoids in the central nervous system: from neuronal networks to behavior. Curr Drug Targets CNS Neurol Disord 4: 633-642.

Fusar-Poli P, Crippa JA, Bhattacharyya S, Borgwardt SJ, Allen P, Martin-Santos R et al (2009). Distinct effects of \{delta\}9tetrahydrocannabinol and cannabidiol on neural activ. Arch Gen Psychiatry 66: 95-105.

Graeff FG (1994). Neuroanatomy and neurotransmitter regulation of defensive behaviors and related emotions in mammals. Braz J Med Biol Res 27: 811-829.

Graeff FG, Brandão ML, Audi EA, Schutz MT (1986). Modulation of the brain aversive system by GABAergic and serotonergic mechanisms. Behav Brain Res 22: 173-180.

Graham ES, Ashton JC, Glass M (2009). Cannabinoid receptors: a brief history and 'what's hot'. Front Biosci 14: 944-957.

Gorman JM, Kent JM, Sullivan GM, Coplan JD (2000). Neuroanatomical hypothesis of panic disorder, revised. Am J Psychiatry 157: 493-505.

Guimarães FS, Chiaretti TM, Graeff F, Zuardi AW (1990). Antianxiety effect of cannabidiol in the elevated plus-maze. Psychopharmacology (Berl) 100: 558-559.

Guimarães-Costa R, Guimarães-Costa MB, Pippa-Gadioli L, Weltson A, Ubiali WA, Paschoalin-Maurin T et al (2007). Innate defensive behavior and panic-like reactions evoked by rodents during aggressive encounters with Brazilian constrictor snakes in a complex labyrinth: behavioural validation of a new model to study affective and agonistic reactions in a prey $v s$ predator paradigm. J Neurosci Meth 165: 25-37.

Griebel G, Blanchard DC, Blanchard RJ (1996). Predator-elicited flight responses in Swiss-Webster mice: an experimental model of panic attacks. Prog Neuro-Psychopharmacol Biol Psychiatry 20: $185-205$.

Izzo AA, Borrelli F, Capasso R, Di Marzo V, Mechoulam R (2009). Non-psychotropic plant cannabinoids: new therapeutic opportunities from an ancient herb. Trends Pharmacol Sci 30: 515-527.
Kellner M, Muhtz C, Demiralay C, Husemann J, Koelsch W, Yassouridis A et al (2009). The selective serotonin re-uptake inhibitor escitalopram modulates the panic response to cholecystokinin tetrapeptide in healthy men depending on 5-HTTLPR genotype. J Psychiatry Res 43: 642-648.

Lisboa SF, Resstel LB, Aguiar DC, Guimarães FS (2008). Activation of cannabinoid CB1 receptors in the dorsolateral periaqueductal gray induces anxiolytic effects in rats submitted to the Vogel conflict test. Eur J Pharmacol 593: 73-78.

Lobão-Soares B, Walz R, Schroder Prediger RD, Freitas RL, Calvo F, Bianchin MM et al (2008). Cellular prion protein modulates defensive attention and innate fear-induced behaviour evoked in transgenic mice submitted to an agonistic encounter with the tropical coral snake Oxyrhopus guibei. Behav Brain Res 194: 129-137.

Mackowiak M, Chocyk A, Dudys D, Wedzony K (2009). Activation of CB1 cannabinoid receptors impairs memory consolidation and hippocampal polysialylated neural cell adhesion molecule expression in contextual fear conditioning. Neurosci 158: $1708-1716$.

Marco EM, Viveros MP (2009). Functional role of the endocannabinoid system in emotional homeostasis. Rev Neurol 48: $20-26$.

Mikics E, Vas J, Aliczki M, Halasz J, Haller J (2009). Interactions between the anxiogenic effects of CB1 gene disruption and $5-\mathrm{HT}_{3}$ neurotransmission. Behav Pharmacol 20: 265-272.

Mishima K, Hayakawa K, Abe K, Ikeda T, Egashira N, Iwasaki K et al (2005). Cannabidiol prevents cerebral infarction via a serotonergic 5-hydroxytryptamine $\mathrm{e}_{1 \mathrm{~A}}$ receptor-dependent mechanism. Stroke 36: 1077-1082.

Mobbs D, Petrovic P, Marchant JL, Hassabis D, Weiskopf N, Seymour B et al (2007). When fear is near: threat imminence elicits prefrontal-periaqueductal gray shifts in humans. Science 314: 1079-1083.

Moreira FA, Aguiar DC, Campos AC, Lisboa SF, Terzian AL, Resstel LB et al (2009a). Antiaversive effects of cannabinoids: is the periaqueductal gray involved? Neural Plast 625-469.

Moreira FA, Grieb M, Lutz B (2009b). Central side-effects of therapies based on CB1 cannabinoid receptor agonists and antagonists: focus on anxiety and depression. Best Pract Res Clin Endocrinol Metab 23: 133-144.

Motta SC, Goto M, Gouveia FV, Baldo MV, Canteras NS, Swanson LW (2009). Dissecting the brain's fear system reveals the hypothalamus is critical for responding in subordinate conspecific intruders. Proc Natl Acad Sci USA 106: $4870-4875$.

Onaivi ES, Ishiguro H, Gong J-J, Patel S, Perchuk A, Meozzi PA et al (2006). Discovery of the presence and functional expression of cannabinoid CB2 receptors in Brain. Proc Natl Acad Sci USA 1074: 514-536.

Pollack MH, Marzol PC (2000). Panic: course, complications and treatment of panic disorder. J Psychopharmacol 14(Suppl 1): S25-S30.

Resstel LB, Lisboa SF, Aguiar DC, Correa FM, Guimarães FS (2008). Activation of CB1 cannabinoid receptors in the dorsolateral periaqueductal gray reduces the expression of contextual fear conditioning in rats. Psychopharmacology (Berl) 198: 405-411.

Resstel LB, Tavares RF, Lisboa SF, Joça SR, Correa FM, Guimarães FS (2009). 5- $\mathrm{HT}_{1 \mathrm{~A}}$ receptors are involved in the cannabidiol-induced attenuation of behavioural and cardiovascular responses to acute restraint stress in rats. Br J Pharmacol 156: $181-188$.

Ribeiro SJ, Ciscato Jr JG, De Oliveira R, de Oliveira RC, d'Ângelo-Dias R, Carvalho $\mathrm{AD}$ et al (2005). Functional and ultrastructural neuroanatomy of interactive intratectal/tectonigral mesencephalic opioid inhibitory links and nigrotectal GABAergic pathways: involvement of $\mathrm{GABA}_{\mathrm{A}}$ and $\mu_{1}$-opioid receptors in 
the modulation of panic-like reactions elicited by electrical stimulation of the dorsal midbrain. J Chem Neuroanat 30: 184-200.

Roser P, Vollenweider FX, Kawohl W (2008). Potential antipsychotic properties of central cannabinoid CB1 receptor antagonists. World J Biol Psychiatry 1-12.

Russo EB, Burnett A, Hall B, Parker KK (2005). Agonistic properties of cannabidiol at $5-\mathrm{HT}_{1 \mathrm{~A}}$ receptors. Neurochem Res 30: $1037-1043$.

Simon NM, Kaufman RE, Hoge EA, Worthington JJ, Herlands NN, Owens ME et al (2009). Open-label support for duloxetine for the treatment of panic disorder. CNS Neurosci Ther 15: 19-23.

Thiemann G, Watt CA, Ledent C, Molleman A, Hasenohrl RU (2009). Modulation of anxiety by acute blockade and genetic deletion of the CB1 cannabinoid receptor in mice together with biogenic amine changes in the forebrain. Behav Brain Res 200: 60-67.

Thomas A, Baillie GL, Phillips AM, Razdan RK, Ross RA, Pertwee RG (2007). Cannabidiol displays unexpectedly high potency as an antagonist of $\mathrm{CB} 1$ and $\mathrm{CB} 2$ receptor agonists in vitro. $\mathrm{Br} \mathrm{J}$ Pharmacol 150: 613-623.

Zarrindast MR, Sarahroodi S, Arzi A, Khodayar MJ, TaheriShalmani S, Rezayof A (2008). Cannabinoid CB1 receptors of the rat central amygdala mediate anxiety-like behavior: interaction with the opioid system. Behav Pharmacol 19: 716-723.

Zuardi AW, Cosme RA, Graeff FG (1993). Effects of ipsapirone and cannabidiol on human experimental anxiety. J Psychopharmacol 7: 82-88.

Zuardi AW (2008). Cannabidiol: from an inactive cannabinoid to a drug with wide spectrum of action. Rev Bras Psiquiatr 30: $271-280$. 